\title{
Postures and Movements in the Most Common Tasks of Power Line Workers
}

\author{
Cristiane Shinohara MORIGUCHI ${ }^{1}$, Letícia CARNAZ ${ }^{1}$, Jeronimo Farias de ALENCAR ${ }^{1}$, \\ Luiz Carlos MIRANDA JÚNIOR ${ }^{2}$, Lothy GRANQVIST ${ }^{3}$, Gert-Åke HANSSON ${ }^{3}$ and \\ Helenice Jane Cote GIL COURY ${ }^{1 *}$
}

\author{
${ }^{1}$ Department of Physical Therapy, Federal University of São Carlos, Washington Luís Road, Km 235, SP310, \\ São Carlos, São Paulo, CEP: 13565-905, Brazil \\ ${ }^{2}$ Center of Technological Higher Education, State University of Campinas, Campinas - SP, Brazil \\ ${ }^{3}$ Division of Occupational and Environmental Medicine, Lund University, Lund, Sweden
}

Received October 7, 2010 and accepted January 27, 2011

Published online in J-STAGE June 21, 2011

\begin{abstract}
The repair and maintenance of electrical power lines involves awkward postures, which are known risk factors for developing musculoskeletal disorders. The aim of the present study was to quantify postures and movements of upper arm, head, upper back and neck in the main tasks performed by line workers. Posture of twelve right-handed line workers was recorded by inclinometry and presented as percentiles of angular and angular velocity distributions. All tasks involved considerable upper-arm elevation, ranging from $73^{\circ}$ to $115^{\circ}$ for the 90th percentile. Upper-arm elevation showed significant differences between tasks, but no consistent differences between right and left sides. Regarding velocity, the right arm presented higher levels than the left arm. All tasks required significant extension of head, upper back and neck, ranging from $7^{\circ}$ to $67^{\circ}$ for head (10th percentile). All tasks, except the one performed with a continuous extension, also involved pronounced flexion, ranging from $33^{\circ}$ to $60^{\circ}$ for the head (90th percentile). Work which required highly elevated arms also required significant head extension $\left(r^{2}=0.56\right)$. Awkward postures of upper arms, head, upper back and neck were identified by inclinometry, demonstrating the need for preventative interventions to reduce musculoskeletal disorders among line workers.
\end{abstract}

Key words: Inclinometry, Shoulder, Head, Neck, Work related musculoskeletal disorders

\section{Introduction}

The use of renewable energy sources should be stimulated in order to change current consumption patterns based on fossil fuels, which are associated with high levels of pollution emission. In recent decades, Brazil has endeavored to increase its use of renewable energy sources, which currently represent $41.3 \%$ of national consumption, compared to an average of $14.4 \%$ for the rest of the world ${ }^{1)}$. Brazilian renewable electricity has a strong hydraulic base and requires an extensive overhead power line network to transmit the energy from

*To whom correspondence should be addressed.

E-mail: helenice@ufscar.br power stations to the consumer. Repairs and maintenance to this network are performed by line workers.

The work conditions of line workers have been associated with a high prevalence of musculoskeletal disorders, elevated medical treatment costs, workers' compensation claims and employee turn-over ${ }^{2}$. These disorders have been associated with stress at work ${ }^{3}$ ) and exposure to weather conditions such as cold environments, which can contribute to the development of musculoskeletal symptoms ${ }^{4}$. Biomechanical risk factors such as the high physical workload due to heavy equipment and tool handling ${ }^{5)}$ and the extreme arm postures adopted on the job ${ }^{2}$ ) have also been investigated in the context of line worker health. Previous studies on such physical risk factors have used systematic observation ${ }^{2,6}$ ) 
and measurements of exerted force and muscular activity $\left.{ }^{5}, 7\right)$. However, no studies using objective measurements to evaluate upper arm and neck posture and movement in line workers were found in the available literature.

Inclinometers can be used to obtain quantitative and generic data on workplace posture and movement. This portable approach enables precise ambulatory and unobtrusive whole-day recordings ${ }^{8,9)}$, providing a basis for kinematic analysis and an understanding of the possible biomechanical risks involved in line workers' activities.

The identification of risk factors by biomechanical assessment can allow ergonomists to design preventative interventions that reduce hazard conditions in the workplace $^{10,11)}$. The accurate quantification of risk factors present in working conditions can also lead to the development of more precise prevention guidelines ${ }^{10,11)}$. Furthermore, the use of biomechanical assessment can both improve the quality of ergonomic interventions for reducing work-related disorders and evaluate the efficacy of implemented interventions ${ }^{12}$.

A previous study on line workers carried out in a Brazilian electrical energy distribution company revealed that $87 \%$ of the evaluated workers presented at least one type of musculoskeletal symptom during the previous 12 months. Shoulder (43\%) and back-related (43\%) symptoms were the most prevalent ${ }^{13}$. Considering these findings, it seems relevant to evaluate, using objective measurements, the kinesiological risk present in these activities.

Thus, the objective of this study was to quantify the upper arm, head, upper back and neck postures and movements required for the most common tasks performed by line workers.

\section{Subjects and Methods}

\section{Subjects and ethical aspects}

Twelve right-handed male line workers (mean age $43 \pm 7.9 \mathrm{yr}$; weight $86 \pm 17 \mathrm{~kg}$; height $1.80 \pm 0.08 \mathrm{~m}$; employment time as a line worker $16 \pm 6.1 \mathrm{yr}$ ) working at an electrical energy distribution company in Brazil participated in the study.

All subjects were informed about the procedures involved in this study and gave their written informed consent. The study was approved by the local ethics committee of the Federal University of São Carlos.

\section{Tasks performed and safety requirements}

Line workers are responsible for repairing and doing maintenance work on low voltage power lines (110 and 220 volt). The work is performed on the ground or on ladders leaning against a pole/attached to a truck.
According to the company safety regulations, when performing their tasks, the line workers should wear special clothes, use a protective helmet and have no contact with any metal object (e.g. watches or rings).

Due to these safety regulations, it was not possible to perform the measurements while the power lines were energized. Thus, the measurements were performed at a technological center for line worker training, where the complete occupational environment is reproduced without active power lines in order to prevent training accidents. At this center, line workers can be trained, periodically re-trained, and become familiarized with new equipment safely. Due to compulsory national regulation legislation, line workers must attend retraining sessions on a regular basis.

\section{Procedures}

Inclinometry

Four inclinometers and a data logger (Logger Teknologi HB, Åkarp, Sweden) were used to record the postures and movements of the right and left upper arms, head, upper back and neck. The sampling rate was $20 \mathrm{~Hz}$. For the upper arms, the inclinometers were attached to plastic plates that were fixed below to the deltoid muscle insertion. For head measurements, the inclinometer is usually fixed to the forehead; however, since there was not enough space inside the helmet, the sensor was attached to the outside of the helmet before the subject put it on. The upper back inclinometer was fixed to the right of the cervicothoracic spine at the C7-T1 level ${ }^{8)}$.

After attaching the inclinometers to the abovedescribed locations, the line workers put on their protective clothes and helmets. Their clothes and helmets were individually adjusted for an exact fit. All inclinometer cables remained beneath the protective clothes. Next, the inclinometers were connected to the data logger and the reference and direction positions were registered. The reference position for the upper arms was obtained while the subject sat with his arms hanging perpendicular to the floor and holding a $2 \mathrm{~kg}$ dumbbell. The reference position for the head and upper back was obtained while the subject stood looking at a mark at his eye level. The forward direction position for the upper arms was set at $90^{\circ}$ of elevation in the scapular plane. The forward direction position for the head and upper back was defined while the subject sat with his neck and trunk flexed ${ }^{14)}$.

Worksite and work tasks

Based on the line workers' productivity schedules, which are records of the main tasks they performed, the following five tasks were determined to be the most fre- 
quent, and were thus selected for evaluation:

a) "Photoelectric relay replacement" (T1): The worker climbed a ladder, removed and substituted a relay with rotating hand movements and then climbed down (Fig. 1A).

b) "Turning a consumer unit off and on" (T2): The worker climbed a ladder at a consumer pole, removed and substituted a connector between two wires with a pair of pliers and climbed down (Fig. 1B).

c) "Lamp replacement" (T3): The worker climbed a ladder attached to a truck to reach a lamp, opened the protective cover, removed and substituted the bulb, closed the protective cover and climbed down (Fig. 1C).

d) "Ladder raising and removal" (T4): This is an auxiliary task consisting of raising the ladder into position before climbing up and removing it after climbing down. The worker took the ladder from its support on the truck, which was at a height of $1.70 \mathrm{~m}$, leaned it against the pole, attached the ladder to the pole with a rope, and then removed the ladder and put it back on the truck support. The ladder weighs $26 \mathrm{~kg}$ (Fig. 1D). e) "100 amp fuse replacement" (T5): The worker substituted a fuse while standing on the ground by using a telescopic stick weighing $6.3 \mathrm{~kg}$ that had a maximum height of $8 \mathrm{~m}$. The worker held the stick perpendicular to the ground and with repetitive arm elevations extended segments to reach the fuse on the top of the pole. The worker maneuvered the telescopic stick to remove the fuse. Next, the worker collapsed the stick segments to retrieve the fuse and substitute it with a new one. Finally, the worker installed the new fuse at the top of the pole and collapsed the telescopic segments once again (Fig. 1E).

To guarantee that all line workers performed the same tasks, a supervisor provided information regarding the order of the tasks to be carried out by the workers, which was randomised.

The total duration of the recordings, including preparation time and transportation between work stations, was about $22 \mathrm{~min}$. The duration of the tasks was similar for all workers, with an average of 2 min $15 \mathrm{~s}$, $4 \min 20 \mathrm{~s}, 2 \min 22 \mathrm{~s}, 2 \mathrm{~min} 20 \mathrm{~s}$, and $4 \mathrm{~min} 1 \mathrm{~s}$ for

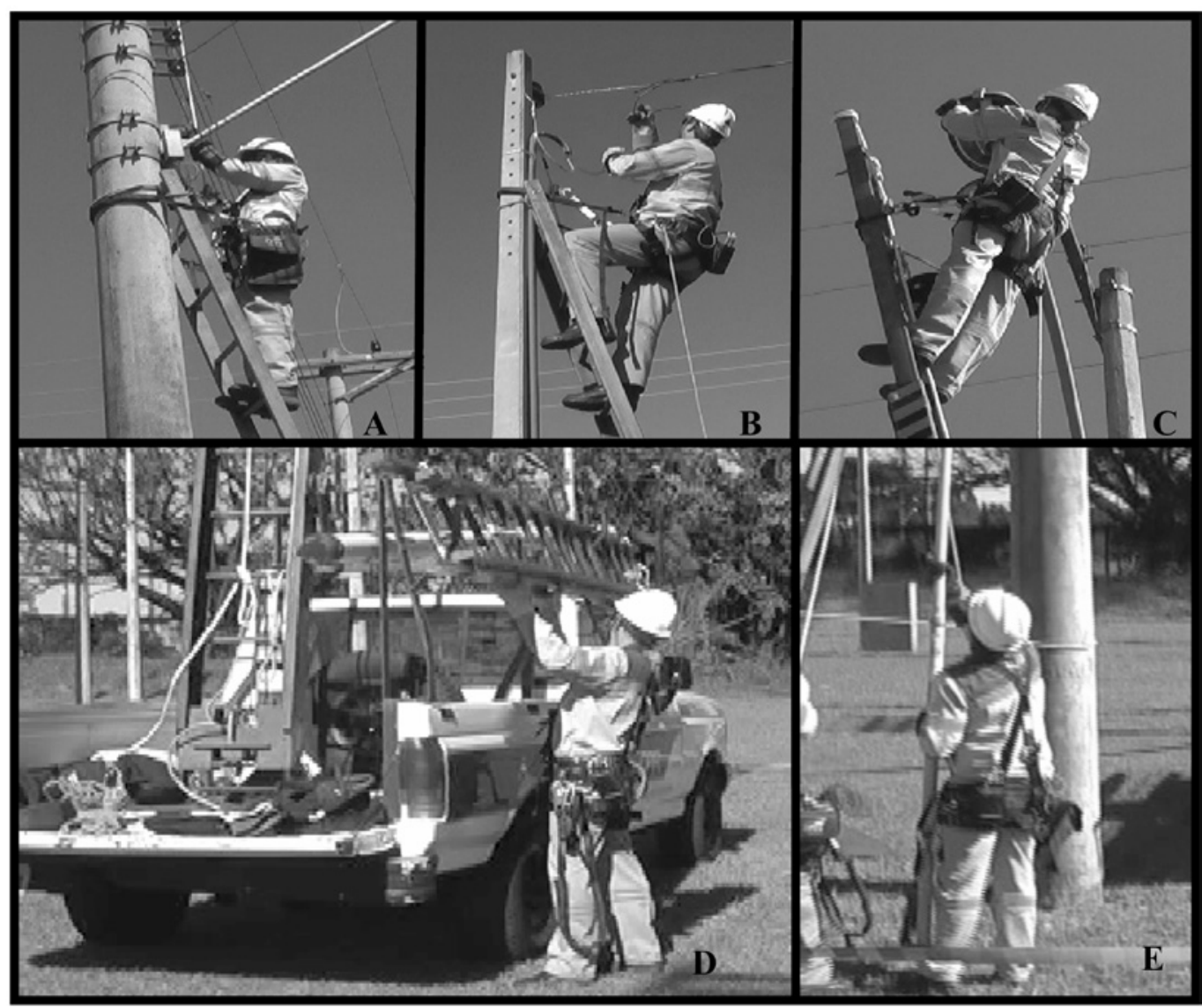

Fig. 1. Line workers performing the five tasks.

A) Photoelectric relay replacement; B) Turning a consumer unit off and on; C) Lamp replacement; D) Ladder raising and removal; E) $100 \mathrm{amp}$ fuse replacement. The photo for E) shows the maneuvering of the lower part of the stick; the fuse is attached to the top of the extended stick. 
tasks T1, T2, T3, T4 and T5, respectively.

In order to verify similarities between the simulated tasks and those performed in the field (real tasks), the duration of some of the tasks performed in the field was observed and timed during regular shift work for 6 workers. The average duration of the real tasks for these 6 workers was $6 \min 14 \mathrm{~s}, 2 \min 32 \mathrm{~s}$ and $2 \min$ $35 \mathrm{~s}$ for tasks T2, T3 and T4, respectively. Not all workers performed tasks 1 and 5 during the observation period. The durations of these three simulated and field tasks can be considered relatively similar, with slightly longer periods necessary for the real activities. The durations of the main tasks, whether real or simulated, were considerably shorter than preparatory tasks such as transportation, marking off the area and material handling.

\section{Data analysis}

For the upper arm elevation angles, the 50th and 90th percentiles of the angular distributions, i.e. the angles exceeded for $50 \%$ and $10 \%$, respectively, of the recording duration, and the fraction of time spent in amplitude zones with the arm elevated above $60^{\circ}$ and $90^{\circ}$ were presented. Flexion/extension angles of the head, upper back and neck were derived for the 10th, 50th and 90th percentiles. As positive values denote flexion and negative extension, the 10th percentile is a measure of extension (lower values correspond to more extended positions), while the 90th percentile is a measure of flexion. For all body regions, the angular velocities were derived from the 50th percentile of the angular velocity distributions. Neck flexion/extension angles and movements were calculated as the difference between the corresponding measures of the head and upper back ${ }^{14)}$. The order of tasks presentation was based on the elevation of the right upper arm (90th percentile). Task exposures were described by the mean value and standard deviation of the 12 workers.

For each posture and movement measurement, differences between tasks were examined using the Friedman test. If this test identified differences $(p<0.05)$, the Wilcoxon signed ranks test with Bonferroni adjustment $(p<0.005)$ was conducted to evaluate the paired differences between tasks. The Spearman correlation coefficient was applied to evaluate the association between head extension and upper arm elevation. All calculations were performed with SPSS v11.5 (SPSS Inc, Chicago, IL, USA).

\section{Results}

\section{Upper arms}

Regarding arm elevation, all workers performed the tasks in a similar way, except for $\mathrm{T} 5$, which displayed scattered values for both the right and left arms (Fig. 2). For this task some of the workers with a very high (or low) elevation on one side showed a very low (or high) elevation on the other side. Hence, the SDs were, for almost all posture measures, conspicuously higher for T5 than for any of the other tasks (Table 1).

Both the right and left upper arms presented high elevations for the five tasks, ranging from $73^{\circ}$ to $115^{\circ}$, for the 90th percentile (Table 1). Line workers maintained high levels of elevation $\left(>60^{\circ}\right)$ for long periods of time, varying from 18 to $69 \%$ of the total task duration, and very high elevations $\left(>90^{\circ}\right) 2 \%$ to $38 \%$ of the time.

The time spent in the different pre-established angular zones varied between the tasks, as did the posture and velocity percentiles (Table 1). Statistical differences were identified between most of the tasks, with all tasks presenting high amplitudes of upper arm elevation, and tasks T3, T4 and T5 presenting very high mean amplitudes. Furthermore, there were significant differences between tasks with respect to velocity, generally speaking. For the right upper arm, velocities ranged from 54 to $94 \%$ s, i.e., a relative difference of $74 \%$. Task T4 was the most dynamic, with angular velocities of $94 \%$ for the right upper arm and $88 \%$ s for the left.

The mean value for the line workers showed, for all elevation measures, symmetric arm elevation during T1, T3 and T4. For the "high end" measures, i.e., the 90th percentile and elevation $>90^{\circ}$, the values for the right arm were considerably higher than those for the left during $\mathrm{T} 2\left(91^{\circ}\right.$ vs. $73^{\circ}$ and $12 \%$ vs. $3.3 \%$; Table 1$)$. The velocities were higher for the right side than for the left side; the relative differences ranged from $7 \%$ to $24 \%$ for the five tasks, and were, on average, $14 \%$ higher for the right side.

\section{Head, upper back and neck}

The tasks primarily influenced head posture, but also had a substantial effect on the upper back (Fig. 3). A considerable fraction of the adaptation was accomplished by flexing and extending the neck. The head, upper back and neck presented both extension (10th percentile) and flexion postures (50th and 90th percentiles) during the performance of tasks T1, T2, T3 and $\mathrm{T} 4$, while in task $\mathrm{T} 5$ extension prevailed, showing the most pronounced negative amplitudes recorded.

The values presented in Table 2 confirm the high amplitudes of head flexion $\left(56^{\circ}\right.$ to $\left.60^{\circ}\right)$ for tasks $\mathrm{T} 1$, $\mathrm{T} 2$ and T3 for the 90th percentile. These tasks also presented high upper back $\left(24^{\circ}\right.$ to $\left.28^{\circ}\right)$ and neck $\left(36^{\circ}\right.$ to $38^{\circ}$ ) flexion amplitudes. In task T5, generally extended postures were observed for all segments and percentiles (except the 90th percentile for the neck), with a con- 
Right upper arm
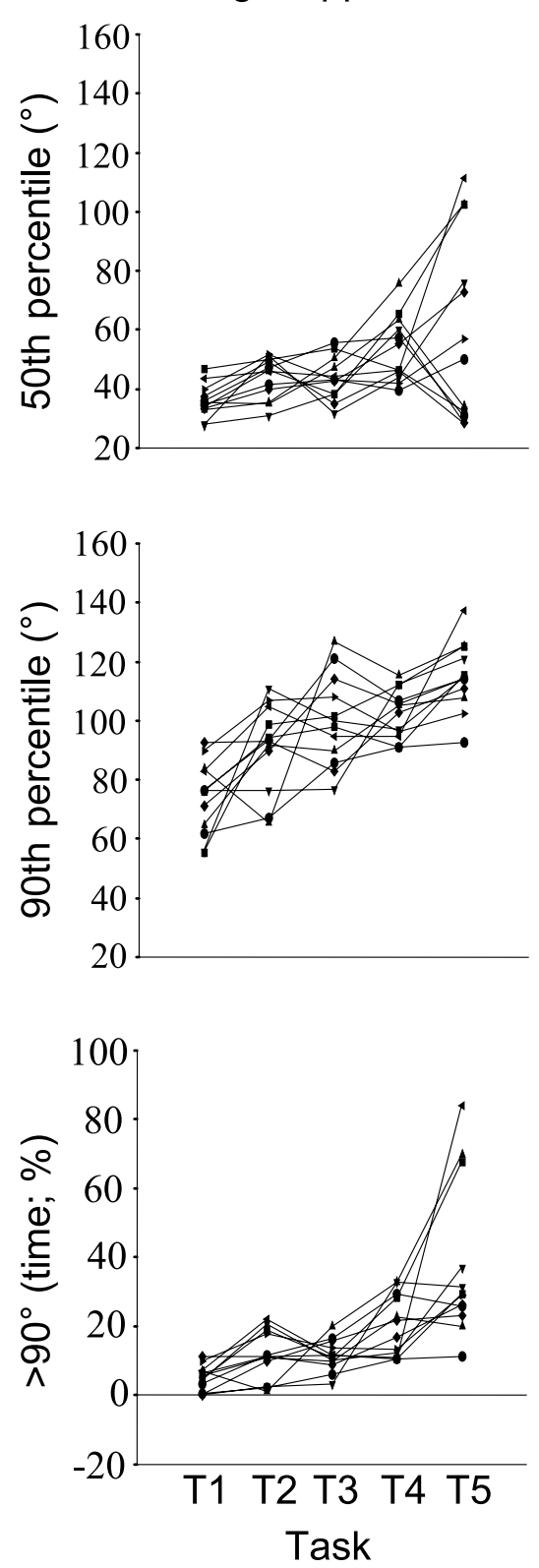

Left upper arm
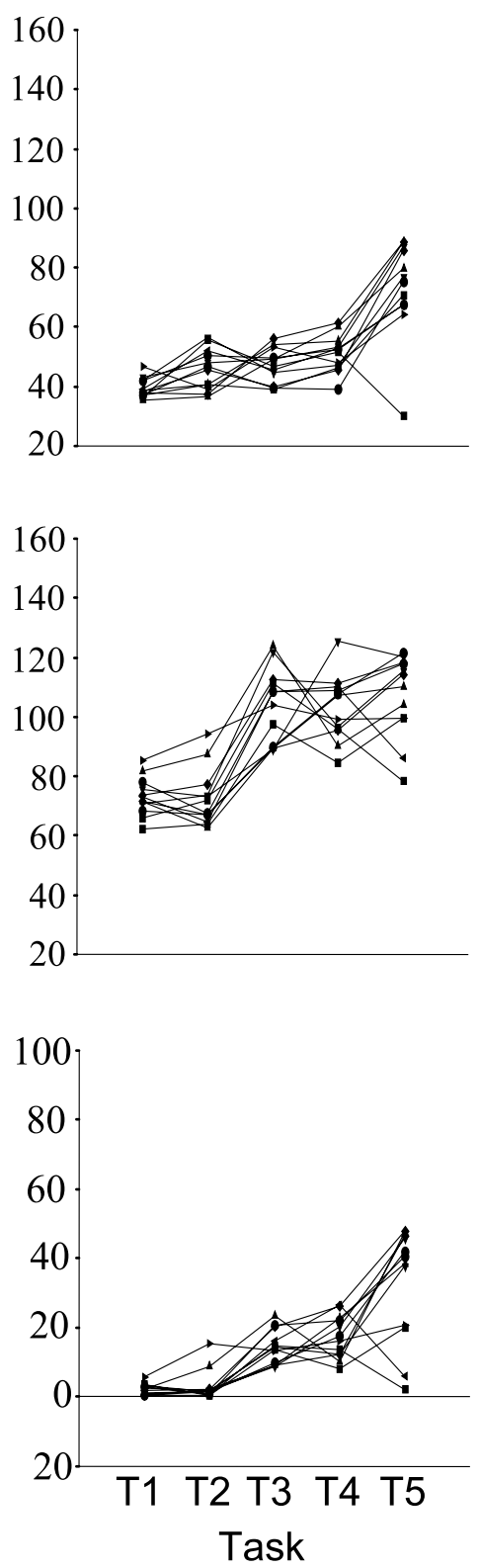

Fig. 2. Right and left upper arm elevation for 12 line workers performing 5 tasks (T1-T5; see Table 1 for explanation).

The 50th and the 90th percentiles and the fraction of time spent with arms elevated more than $90^{\circ}$ are presented. For each worker, the data are connected by lines.

spicuous head extension of $-67^{\circ}$ for the 10th percentile. The tasks were significantly different for most of the amplitudes and velocities evaluated, except for some T1, $\mathrm{T} 2$ and T3 values. Regarding velocity, T4 was, as with the upper arm measurements, significantly more dynamic than the other tasks.

Considering all tasks jointly, working with elevated arms was associated with head extension. The Spearman correlation between head extension (10th percentile) and upper arm elevation (90th percentile) was $-0.75(p<0.01)$.

\section{Inter-subjects variability}

The inter-subjects variability (SD) for head, back and neck postures, which ranged from $4^{\circ}$ to $14^{\circ}$, showed no obvious differences according to task or body region. On the other hand, the upper arms presented intersubjects variability ranging from $3^{\circ}$ to $32^{\circ}$, with Task 5 exhibiting higher levels of variability for the upper arms than other tasks (see above). 
Table 1. Postures and movements for the right and left upper arms of the $\mathbf{1 2}$ line workers while performing $\mathbf{5}$ tasks.

\begin{tabular}{|c|c|c|c|c|c|c|c|c|c|c|c|c|c|c|c|c|c|c|c|c|c|}
\hline \multirow[t]{4}{*}{ Postures and movements } & & \multicolumn{20}{|c|}{ Task* } \\
\hline & & \multicolumn{6}{|c|}{$\mathrm{T} 1$} & \multicolumn{5}{|c|}{$\mathrm{T} 2$} & \multicolumn{4}{|c|}{ T3 } & \multicolumn{3}{|c|}{$\mathrm{T} 4$} & \multicolumn{2}{|c|}{ T5 } \\
\hline & & \multirow[t]{2}{*}{ M } & \multirow[t]{2}{*}{ (SD) } & \multicolumn{4}{|c|}{$\mathrm{D}$} & \multirow[t]{2}{*}{ M } & \multirow[t]{2}{*}{ (SD) } & \multicolumn{3}{|c|}{$\mathrm{D}$} & \multirow[t]{2}{*}{ M } & \multirow[t]{2}{*}{ (SD) } & \multicolumn{2}{|c|}{$\mathrm{D}$} & \multirow[t]{2}{*}{ M } & \multirow[t]{2}{*}{ (SD) } & \multirow{2}{*}{$\frac{\mathrm{D}}{\mathrm{T} 5}$} & \multirow[t]{2}{*}{ M } & \multirow[t]{2}{*}{ (SD) } \\
\hline & & & & $\mathrm{T} 2$ & T3 & $\mathrm{T} 4$ & T5 & & & $\mathrm{T} 3$ & $\mathrm{~T} 4$ & T5 & & & $\mathrm{T} 4$ & T5 & & & & & \\
\hline \multicolumn{22}{|l|}{ Right upper arm elevation } \\
\hline \multirow[t]{2}{*}{ Posture Percentile $\left({ }^{\circ}\right)$} & 50th & 36 & (6) & $\checkmark$ & $\checkmark$ & $\checkmark$ & & 44 & (7) & & & & 44 & (7) & & & 53 & (11) & & 61 & (32) \\
\hline & 90th & 74 & (12) & & $\checkmark$ & $\checkmark$ & $\checkmark$ & 91 & (15) & & & $\checkmark$ & 100 & (15) & & & 103 & (8) & $\checkmark$ & 115 & (12) \\
\hline \multirow[t]{2}{*}{ Zone (\% time) } & $>60^{\circ}$ & 18 & (7.3) & & $\checkmark$ & $\checkmark$ & $\checkmark$ & 31 & (10) & & & $\checkmark$ & 30 & (8.9) & & $\checkmark$ & 42 & (13) & & 57 & (23) \\
\hline & $>90^{\circ}$ & 5.1 & (3.7) & & $\checkmark$ & $\checkmark$ & $\checkmark$ & 12 & (7.1) & & & $\checkmark$ & 12 & (4.6) & & $\checkmark$ & 20 & $(9.0)$ & & 38 & (23) \\
\hline Velocity Percentile $(\%)$ & 50th & 67 & (17) & $\checkmark$ & & $\checkmark$ & & 56 & (14) & & $\checkmark$ & & 72 & (15) & $\checkmark$ & $\checkmark$ & 94 & (14) & $\checkmark$ & 54 & (13) \\
\hline \multicolumn{22}{|l|}{ Left upper arm elevation } \\
\hline \multirow[t]{2}{*}{ Posture Percentile $\left(^{\circ}\right)$} & 50th & 39 & (3) & & $\checkmark$ & $\checkmark$ & $\checkmark$ & 46 & (7) & & & & 47 & (6) & & $\checkmark$ & 51 & (6) & & 73 & (16) \\
\hline & 90th & 73 & (6) & & $\checkmark$ & $\checkmark$ & $\checkmark$ & 73 & (10) & $\checkmark$ & $\checkmark$ & $\checkmark$ & 104 & (13) & & & 103 & (11) & & 107 & (14) \\
\hline \multirow[t]{2}{*}{ Zone (\% time) } & $>60^{\circ}$ & 23 & (7.0) & & $\checkmark$ & $\checkmark$ & $\checkmark$ & 26 & $(8.5)$ & & & $\checkmark$ & 33 & (7.6) & & $\checkmark$ & 39 & (7.6) & $\checkmark$ & 69 & (15) \\
\hline & $>90^{\circ}$ & 2.2 & (1.6) & & $\checkmark$ & $\checkmark$ & $\checkmark$ & 3.3 & (4.4) & $\checkmark$ & $\checkmark$ & $\checkmark$ & 15 & $(4.9)$ & & & 17 & (6.2) & & 33 & (16) \\
\hline Velocity Percentile $(\% / s)$ & 50th & 59 & (12) & $\checkmark$ & & $\checkmark$ & & 45 & (12) & $\checkmark$ & $\checkmark$ & & 67 & (14) & $\checkmark$ & $\checkmark$ & 88 & (14) & $\checkmark$ & 45 & (8.2) \\
\hline
\end{tabular}

Mean (M) and, within brackets, standard deviations (SD) are shown for the 50th and 90th percentiles of arm elevation, as well as the fraction of time spent in angular zones exceeding $60^{\circ}$ and $90^{\circ}$. The 50th percentiles for the angular velocities are also shown. Statistically significant differences between tasks (D) were tested for paired comparisons with the Wilcoxon Signed Ranks Test, with Bonferroni adjustment $(p<0.005)$.

*T1 = "Photoelectric relay replacement"; T2 = "Turning a consumer unit off and on"; T3 = "Lamp replacement"; T4 = "Ladder raising and removal"; T5 = "100 amp fuse replacement". $\checkmark=$ Statistically signifcant difference.

Since the SDs increased with increasing mean values, the inter-subject variability for velocity was evaluated by the $\mathrm{CV}$ s, i.e., the SD divided by the mean value. The $\mathrm{CV}$ of the right and left upper arms, head, upper back and neck ranged from $12 \%$ to $27 \%$, with a mean value of $21 \%$ for the five body regions and the five tasks.

\section{Discussion}

\section{Upper arms}

High values of arm elevation were identified for all tasks. The 90th percentile and elevation $>90^{\circ}$ are measures of the high end of angular distribution, and more specific for quantifying the occurrence of highly elevated arms. There is no consensual safe limit for shoulder elevation at work available in the literature. One of the possible reasons for this is the fact that postural risks can be potentialized by other simultaneous biomechanical aspects present in workplaces, such as exerted force ${ }^{15)}$, repetition ${ }^{16)}$ and psychosocial factors such as mental demands ${ }^{17}$ ). Nevertheless, it has been widely recognized that high amplitudes of shoulder flexion and abduction are strongly associated with musculoskeletal disorders ${ }^{18,}{ }^{19)}$. Different safe limits have been proposed for a number of years. Since the 1970s, published studies have reported that shoulder angles above $30^{\circ}$ require substantial supraspinatus and deltoid muscle activity ${ }^{19}$ ). Although recommendations differ, postures with shoulder abduction or flexion above $60^{\circ}$ are considered awkward in most of the available studies. Considering, moreover, that this cut-off point was considered the safe limit of upper arm elevation by ISO11226 ${ }^{20)}$, it was adopted in the present study, along with $90^{\circ}$, as an anchor point for the description and interpretation of the results. The $90^{\circ}$ angle was adopted as a critical cut-off, since a clear relationship has been found between jobs involving lifetime upper arm elevation and objective signs of supraspinatus tendinopathy ${ }^{21)}$. Moreover, Svendsen et al. ${ }^{22)}$ found a quantitative exposure-response relation between arm elevation and supraspinatus tendinitus.

According to pathophysiological mechanisms, two risk factors could lead to work-related disorders at shoulder in high arm elevation tasks. One factor is the maintenance of muscle activation, which leads to increased muscle pressure, a reduction in blood circulation and decreases in oxygenation and $\mathrm{Ca}^{2+}$ accumulation, which consequently result in morphological changes to the muscles. The other factor is awkward posture, which leads to mechanical load on tendons and peripheral nerves and may cause tissue damage ${ }^{23}$.

Task T5 was the most critical, since the line workers spent more than $30 \%$ of its duration with their arms above $90^{\circ}$. The high amplitudes in this task seem to have occurred while the line workers, working from the ground level, substituted fuses at the top of the pole. Workers usually do not use ladders for this task because it is very short, taking only a couple of minutes to accomplish. However, considering the extreme postures present in this activity, it should be redesigned to reduce 

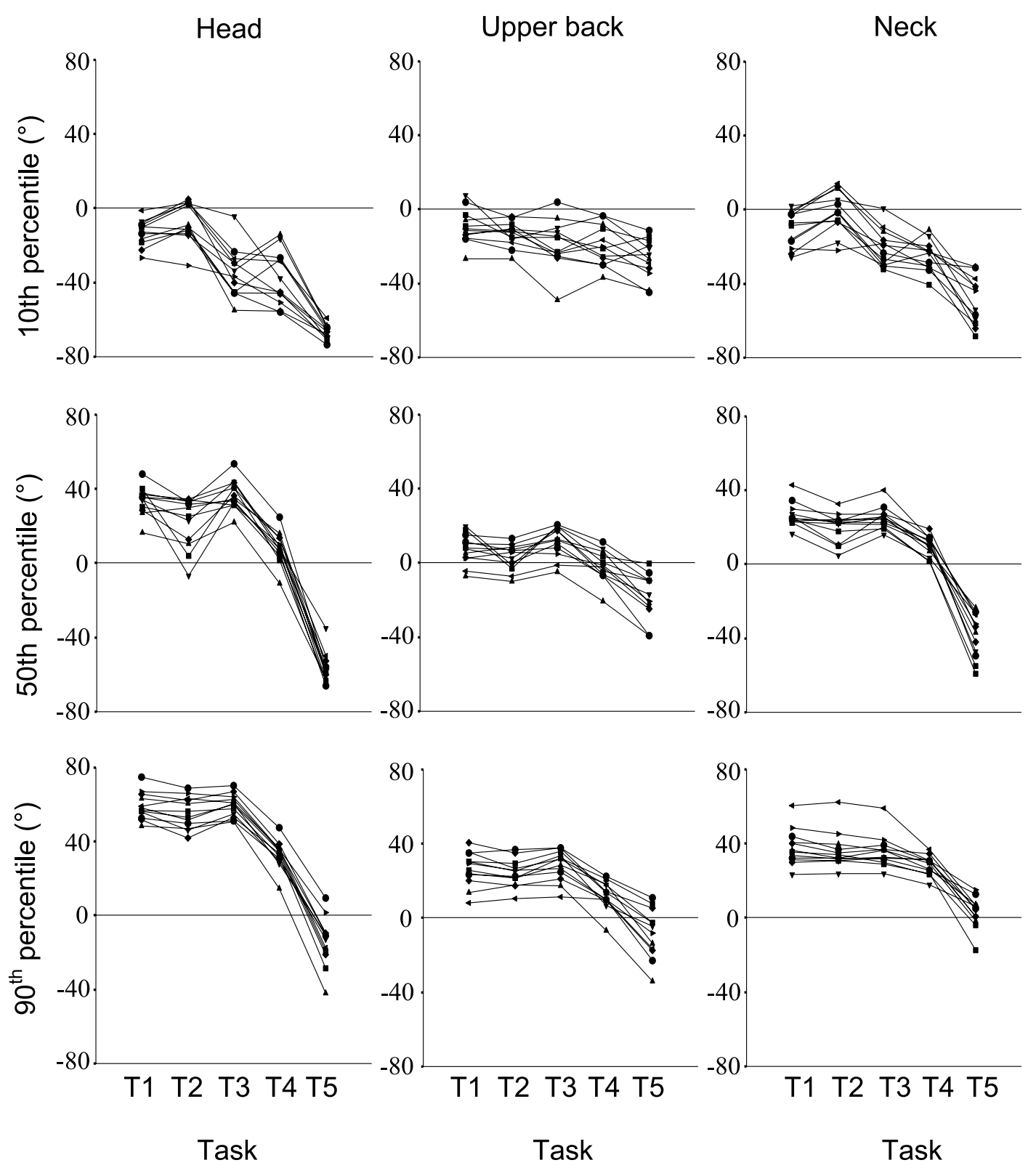

Fig. 3. Flexion/extension angles for head, upper back and neck for 12 line workers performing 5 tasks (T1-T5; see Table 2 for explanation).

The 10th, 50th and 90th percentiles are presented. For each worker, the data are connected by lines. Positive values denote flexion, and negative values, extension.

risks. Possible design alternatives could include the use of ladders attached to the truck or changes to the telescoping stick in accordance with job safety requirements.

The generally higher velocity (14\%) for the right arm indicates a higher risk for the dominant arm than the non-dominant one. Still, even among the rather similar tasks, the differences were considerably high (74\%), indicating that the tasks themselves are a more important factor than right-handedness for developing musculoskeletal disorders. Right-handedness had a significant influence on elevation in only two of the five tasks, which isolates the task as the primary target for intervention.

For standardized tasks repeated on separate occasions, Hansson et al. ${ }^{14)}$ reported an inter-subjects variability (calculated by adding the inter-day and inter-subject variances) of $5.2^{\circ}(\mathrm{SD})$ for angles described by percentiles and $23 \%(\mathrm{CV})$ for velocities. In spite of safety regulations, the presence of a trainer during task performance and the uniform environment at the training center - all of which should have obliged the workers 
Table 2. Postures and movements for head, upper back and neck for the 12 line workers performing 5 tasks.

\begin{tabular}{|c|c|c|c|c|c|c|c|c|c|c|c|c|c|c|c|c|c|c|c|c|c|}
\hline \multirow[t]{4}{*}{ Postures and movements } & & \multicolumn{20}{|c|}{ Task* } \\
\hline & & \multicolumn{6}{|c|}{$\mathrm{T} 1$} & \multicolumn{5}{|c|}{$\mathrm{T} 2$} & \multicolumn{4}{|c|}{$\mathrm{T} 3$} & \multicolumn{3}{|c|}{$\mathrm{T} 4$} & \multicolumn{2}{|c|}{ T5 } \\
\hline & & \multirow[t]{2}{*}{ M } & \multirow[t]{2}{*}{ (SD) } & \multicolumn{4}{|c|}{$\mathrm{D}$} & \multirow[t]{2}{*}{ M } & \multirow[t]{2}{*}{ (SD) } & \multicolumn{3}{|c|}{$\mathrm{D}$} & \multirow[t]{2}{*}{ M } & \multirow[t]{2}{*}{ (SD) } & \multicolumn{2}{|c|}{$\mathrm{D}$} & \multirow[t]{2}{*}{ M } & \multirow[t]{2}{*}{ (SD) } & \multirow{2}{*}{$\begin{array}{c}\mathrm{D} \\
\mathrm{T} 5 \\
\end{array}$} & \multirow[t]{2}{*}{ M } & \multirow[t]{2}{*}{ (SD) } \\
\hline & & & & $\mathrm{T} 2$ & $\mathrm{~T} 3$ & $\mathrm{~T} 4$ & T5 & & & $\mathrm{T} 3$ & $\mathrm{~T} 4$ & T5 & & & $\mathrm{T} 4$ & $\mathrm{~T} 5$ & & & & & \\
\hline \multicolumn{22}{|l|}{ Head flexion } \\
\hline \multirow[t]{3}{*}{ Posture Percentile $\left(^{\circ}\right)$} & 10th & -13 & (7) & & $\checkmark$ & $\checkmark$ & $\checkmark$ & -7 & (11) & $\checkmark$ & $\checkmark$ & $\checkmark$ & -35 & (13) & & $\checkmark$ & -38 & (14) & $\checkmark$ & -67 & (4) \\
\hline & 50th & 34 & (8) & & & $\checkmark$ & $\checkmark$ & 22 & (14) & $\checkmark$ & & $\checkmark$ & 37 & (8) & $\checkmark$ & $\checkmark$ & 9 & (9) & $\checkmark$ & -57 & (8) \\
\hline & 90th & 59 & (7) & & & $\checkmark$ & $\checkmark$ & 56 & (9) & & $\checkmark$ & $\checkmark$ & 60 & (6) & $\checkmark$ & $\checkmark$ & 33 & (8) & $\checkmark$ & -14 & (13) \\
\hline Velocity Percentile $(\% / \mathrm{s})$ & 50th & 24 & $(5.0)$ & $\checkmark$ & & $\checkmark$ & & 19 & (3.8) & $\checkmark$ & $\checkmark$ & $\checkmark$ & 25 & $(3.7)$ & $\checkmark$ & & 37 & $(4.6)$ & $\checkmark$ & 26 & $(6.0)$ \\
\hline \multicolumn{22}{|l|}{ Upper back flexion } \\
\hline \multirow[t]{3}{*}{ Posture Percentile $\left(^{\circ}\right)$} & 10th & -9 & (9) & & & $\checkmark$ & $\checkmark$ & -13 & (7) & & & $\checkmark$ & -19 & (13) & & & -19 & (11) & & -27 & (11) \\
\hline & 50th & 7 & (8) & & & & $\checkmark$ & 3 & (7) & $\checkmark$ & & $\checkmark$ & 12 & (8) & $\checkmark$ & $\checkmark$ & -2 & (8) & $\checkmark$ & -18 & (12) \\
\hline & 90th & 26 & (9) & & & $\checkmark$ & $\checkmark$ & 24 & (7) & $\checkmark$ & $\checkmark$ & $\checkmark$ & 28 & (8) & $\checkmark$ & $\checkmark$ & 12 & (8) & $\checkmark$ & -8 & (13) \\
\hline Velocity Percentile ( $\%$ s) & 50th & 21 & (4.7) & $\checkmark$ & & $\checkmark$ & $\checkmark$ & 15 & (3.6) & $\checkmark$ & $\checkmark$ & & 22 & $(4.3)$ & $\checkmark$ & $\checkmark$ & 30 & (4.6) & $\checkmark$ & 14 & $(2.7)$ \\
\hline \multicolumn{22}{|l|}{ Neck flexion } \\
\hline \multirow[t]{3}{*}{ Posture Percentile $\left({ }^{\circ}\right)$} & 10th & -10 & (10) & $\checkmark$ & & & $\checkmark$ & -1 & (11) & $\checkmark$ & $\checkmark$ & $\checkmark$ & -21 & (10) & & $\checkmark$ & -25 & (8) & $\checkmark$ & -49 & (13) \\
\hline & 50th & 27 & (7) & $\checkmark$ & & $\checkmark$ & $\checkmark$ & 20 & (8) & & & $\checkmark$ & 25 & (6) & $\checkmark$ & $\checkmark$ & 10 & (5) & $\checkmark$ & -38 & (12) \\
\hline & 90th & 38 & (10) & & & $\checkmark$ & $\checkmark$ & 36 & (10) & & $\checkmark$ & $\checkmark$ & 36 & (9) & $\checkmark$ & $\checkmark$ & 28 & (5) & $\checkmark$ & 3 & (8) \\
\hline Velocity Percentile ( $\%$ s) & 50th & 18 & $(5.0)$ & & & $\checkmark$ & $\checkmark$ & 16 & (4.0) & & $\checkmark$ & $\checkmark$ & 18 & (3.5) & $\checkmark$ & $\checkmark$ & 36 & (5.5) & $\checkmark$ & 26 & (6.4) \\
\hline
\end{tabular}

Mean (M) and, within brackets, standard deviations (SD) are shown for the 10th, 50th and 90th percentiles of flexion/extension. Statistically significant differences between tasks (D) were tested for paired comparisons with Wilcoxon Signed Ranks Test, with Bonferroni adjustment $(p<0.005)$.

*T1 = "Photoelectric relay replacement"; T2 = "Turning a consumer unit off and on"; T3 = "Lamp replacement"; T4 = "Ladder raising and removal"; T5 = "100 amp fuse replacement". $\checkmark$ = Statistically significant difference.

to carry out the tasks in a standardized manner- the variation for all tasks was higher than the $5.2^{\circ}$ reported by Hansson et $a l^{14)}$. The high variability in angles observed during T5 is presumably explained by individual preference for maintaining either the right or the left upper arm higher during the stick maneuver. Moreover, in the real workplace variability may be higher still due to different conditions such as the presence of parked vehicles, trees, and other interference. On the other hand, the variation in movement $(21 \%)$ was surprisingly lower than for the standardized tasks above.

\section{Head, upper back and neck}

High amplitudes of head and neck flexion were identified for tasks T1, T2 and T3, and pronounced extension was identified for all tasks, especially for T5. Several studies have described a strong association between awkward or extreme postures involving the head and neck and risks for developing work-related musculoskeletal disorders $\left.{ }^{19}, 24-26\right)$. Harms-Ringdahl et al. ${ }^{27)}$ calculated the loading moments of force on the bilateral motion axis of spinal cervico-thoracic motion during extreme neck positions and reported that the load moment when the whole neck was flexed was 3 to 6 times the value for the neutral position. On the other hand, Sakakibara et al. ${ }^{28)}$ observed farmers fully extending their necks during overhead fruit cultivation work (the opposite situation) and concluded that such working postures may lead to symptoms of vertebral artery insuf- ficiency. According to ISO1122620) and Ariëns et al. ${ }^{29)}$, head postures should be kept in between $0^{\circ}$ and $25^{\circ}$ of flexion to avoid unfavorable positions. According to these recommendations, the levels of head and neck flexion and extension during line worker activity should be reduced.

The strong association between high levels of upper arm elevation and extensive head/neck extension was somewhat expected because the focus of some activities was further above shoulder level. In these cases, an increase of postural load for both joints is likely, which can raise the risks for developing shoulder-neck disorders ${ }^{30)}$. Moreover, the extension movements of the lower back observed during overhead work increase trunk moments, muscular activity and spinal load ${ }^{31)}$, which could lead to disc herniations if repetitive flexion and extension motion occurs ${ }^{32}$ ). Thus, the redesign of these tasks should take into account the collective risks for different body regions.

The results of the present study allowed the precise quantification of posture and movement during the principal occupational activities of line workers. Task 5 must be redesigned in order to reduce the extreme postures for upper-arm elevation and, head, upper back and neck extension. After the implementation of a new task design, the intervention outcomes should be compared to the previous conditions to check for efficacy.

Another relevant preventative intervention would be to provide worksite exercise for the line workers, since 
even redesigned tasks can expose them to risk factors. The use of exercise at the workplace to prevent musculoskeletal disorders has been considered effective ${ }^{33}, 34$, particularly if supervised, carried out for at least $10 \mathrm{wk}$, performed 2 to 3 times a week and if strengthening exercises are also included ${ }^{35}$.

\section{Methodological considerations}

The absence of electrical current had probably only a minor, if any, effect on subject performance, since they performed the tasks following their usual procedures. Affixing the inclinometer to the helmet instead of the forehead could have introduced only limited errors due to helmet movements, since the helmet was wellsecured to the head with straps and each line worker used his own personal helmet. Moreover, the reference and direction positions were registered after the helmet was secured to worker's head, and the helmet was not removed during the entire recording session. The aim of the recordings was to characterize common tasks, and the supplementary, less demanding activities (preliminary actions performed before tasks) were not included in the recordings. Hence, the presented data show higher exposures and do not represent overall job exposure.

The risks present in line work are both diverse and complex, including lethal risks from electrical hazards and falls. The biomechanical risks are multifaceted and, in future studies, additional simultaneous measurements of exerted force, e.g. by electromyography, could be used to provide information for more comprehensive interventions. To this end, whole-day recordings, which, in addition to task exposure, also provide data on job exposure and exposure variation, are suitable.

\section{Conclusion}

The objective recording of movement was a useful tool for providing ergonomists with precise results. There were significant differences between the tasks analyzed. Nevertheless, awkward postures of the upper arms, upper back, head and neck occurred during all activities. Ergonomic redesign of the job is needed to prevent musculoskeletal disorders among workers.

\section{Acknowledgements}

To FAPESP Process Number 2008/10399-0 and Process Number 2008/10372-4.

\section{References}

1) Goldemberg J, Lucon O (2007) Energy and environment in Brazil. Advanced Studies 59, 7-20.
2) Seeley PA, Marklin RW (2003) Business case for implementing two ergonomic interventions at an electric power utility. Appl Ergon 34, 429-39.

3) Martinez MC, Fischer FM (2009) Stress at work among electric utility workers. Ind Health 47, 55-63.

4) Inaba R, Mirbord SM (2010) Subjective musculoskeletal symptoms in winter and summer among indoor working construction electricians. Ind Health 48, 29-37.

5) Parkhouse W, Gall B (2004) Task frequency as a function of age for the powerline technician trade. Ergonomics 47, 660-70.

6) Graves RJ, de Cristofano A, Wright E, Watt M, White $R$ (1996) Potential musculoskeletal risk factors in electricity distribution linesman tasks. Contemporary Ergonomics 1, 215-20.

7) Marklin RW, Yager J (2004) EPRI Ergonomic handbook for the electric power industry: ergonomic interventions for manhole, vault and conduit applications. USA, Palo Alto, CA: EPRI 1005430.

8) Hansson G-Å, Asterland P, Holmer N-G, Skerfving S (2001) Validity and reliability of triaxial accelerometer for inclinometry in posture analysis. Med Biol Eng Comput 39, 405-13.

9) Bernmark E, Wiktorin C (2002) A triaxial accelerometer for measuring arm movements. Appl Ergon 33, 541-7.

10) Garg A, Kapellusch JM (2009) Applications of biomechanics for prevention of work-related musculoskeletal disorders. Ergonomics 52, 36-59.

11) Burdorf A (2010) The role of assessment of biomechanical exposure at the workplace in the prevention of musculoskeletal disorders. Scand J Work Environ Health 36, 1-2.

12) Rodacki ALF, Vieira JE (2010) The effect of different supermarket checkout workstations on trunk kinematics of checkout operators. Braz J Phys Ther 14, 38-44.

13) Moriguchi CS, Alencar JF, Miranda Júnior LC, Gil Coury HJC (2009) Musculoskeletal symptoms among energy distribution network linemen. Braz J Phys Ther 13, 123-9.

14) Hansson G- $\AA$, Arvidsson I, Ohlsson K, Nordander C, Mathiassen SE, Skerfving S, Balogh I (2006) Precision of measurements of physical workload during standardised manual handling. Part II: Inclinometry of head, upper back, neck and upper arms. J Electromyogr Kinesiol 16, 125-36.

15) Brookham RL, Wong JM, Dickerson CR (2010) Upper limb posture and submaximal hand tasks influence shoulder muscle activity. Int J Ind Ergon 40, 337-44.

16) Ebaugh DD, McClure PW, Karduna AR (2006) Effects of shoulder muscle fatigue caused by repetitive overhead activities on scapulothoracic and glenohumeral kinematics. J Electromyogr Kinesiol 16, 224-35.

17) Jensen BR, Laursen B, Sjøgaard G (2000) Aspects of shoulder function in relation to exposure demands and 
fatigue - a mini review. Clin Biomech 15, S17-S20.

18) Kuorinka I, Forcier L (1995) Work Related Musculoskeletal Disorders (WRMDs): A reference book for prevention, 1st Ed., Taylor \& Francis, London.

19) Bernard B (1997) Musculoskeletal disorders and workplace factors - a critical review of epidemiologic evidence for work-related musculoskeletal disorders of the neck, upper extremity, and low back. National Institute for Occupational Safety and Health, DHHS (NIOSH) Publication No. 97-141.

20) Delleman NJ, Dul J (2007) International standards on working postures and movements ISO 11226 and EN 1005-4. Ergonomics 50, 1809-19.

21) Svendsen S, Gelineck J, Mathiassen SE, Bonde J, Frich L, Stengaard-Pedersen K, Egund N (2004) Work above shoulder level and degenerative alterations of the rotator cuff tendons: a magnetic resonance imaging study. Arthritis Rheum 50, 3314-22.

22) Svendsen SW, Bonde JP, Mathiassen SE, StengaardPedersen K, Frich LH (2004) Work related shoulder disorders: quantitative exposure-response relations with reference to arm posture. Occup Environ Med 61, $844-53$.

23) Staal JB, de Bie RA, Hendriks EJM (2007) Aetiology and management of work-related upper extremity disorders. Best Pract Res Clin Rheumatol 21, 123-33.

24) Van den Heuvel SG, van der Beek BM, Blatter BM, Bongers PM (2006) Do work-related physical factors predict neck and upper limb symptoms in office workers? Int Arch Occup Environ Health 79, 585-92.

25) Larsson B, Søgaard K, Rosendal L (2007) Work related neck-shoulder pain: a review on magnitude, risk factors, biomechanical characteristics, clinical picture and preventive interventions. Best Pract Res Clin Rheumatol 21, 447-63.

26) Palmer KT, Smedley DM (2007) Work relatedness of chronic neck pain with physical findings- a system- atic review. Scand J Work Environ Health 33, 165-91.

27) Harms-Ringdahl K, Ekholm J, Schüldt K, Németh G, Arborelius U (1986) Load moments and myoelectric activity when the cervical spine is held in full flexion and extension. Ergonomics 29, 1539-52.

28) Sakakibara H, Miyao M, Kondo T, Yamada S, Nakagawa T, Kobayashi F (1987) Relation between overhead work and complaints of pear and apple orchard workers. Ergonomics 30, 805-15.

29) Ariëns GAM, Bongers PM, Douwes M, Miedema MC, Hoogendoorn WE, van der Wal G, Bouter LM, van Mechelen W (2007) Are neck flexion, neck rotation, and sitting at work risk factors for neck pain? Results of a prospective cohort study. Occup Environ Med 58, 200-7.

30) Winkel J, Westgaard R (1992) Occupational and individual risk factors for shoulder-neck complaints: Part II -The scientific basis (literature review) for the guide. Int J Ind Ergon 10, 85-104.

31) Davis KG, Marras WS (2000) The effects of motion on trunk biomechanics. Review paper. Clin Biomech 15, 703-17.

32) Calaghan JP, McGill SM (2001) Intervertebral disc herniation: studies on a porcine model exposed to highly repetitive flexion/extension motion with compressive force. Clin Biomech 16, 28-37.

33) Silverstein B, Clark R (2004). Interventions to reduce work-related musculoskeletal disorders. J Electromyogr Kinesiol 14, 135-52.

34) van Poppel MNM, Hooftman WE, Koes BW (2004) An update of a systematic review of controlled clinical trials on the primary prevention of back pain at the workplace. Occup Med 54, 345-52.

35) Gil Coury HJC, Moreira RFC, Dias NB (2009) Evaluation of the effectiveness of workplace exercise in controlling neck, shoulder and low back pain: a systematic review. Braz J Phys Ther 13, 461-79. 